\title{
Stark broadening measurements of low-intensity singly and doubly ionized xenon spectral lines
}

\author{
R. J. Peláez ${ }^{1}$, M. Ćirišan ${ }^{2}$, S. Djurović ${ }^{2}$ J. A. Aparicio ${ }^{1}$, and S. Mar ${ }^{1}$ \\ ${ }^{1}$ Departamento de Física Teórica, Atómica y Óptica, Universidad de Valladolid, 47071 Valladolid, Spain \\ e-mail: apa@opt.uva.es \\ 2 Faculty of Sciences, Department of Physics, Trg Dositeja Obradovića 4, 21000 Novi Sad, Serbia
}

Received 6 July 2009 / Accepted 31 August 2009

\begin{abstract}
Aims. The aim of this work is to provide Stark parameters of low intensity Xe II and Xe III spectral lines from which scarce or null previous information exist.This work completes the measurements of ionized Xenon parameters developed in the last few years and extends Stark parameters database for astrophysical applications.

Methods. All Stark parameters were measured in a pulsed arc plasma with $95 \%$ of helium and $5 \%$ of xenon. Measured electron densities and temperatures were in the range of $(0.2-1.7) \times 10^{23} \mathrm{~m}^{-3}$ and $18000-25500 \mathrm{~K}$, respectively.

Results. As a whole 25 Stark widths and 29 shifts of Xe II spectral lines have been measured, along with 10 Stark widths and 6 shifts of Xe III. Some of the presented data are compared to theoretical values calculated using modified semiempirical formulae, as well as to other available experimental results.
\end{abstract}

Key words. plasmas - atomic data - line: profiles

\section{Introduction}

Stark broadening of singly and doubly ionized xenon spectral lines has been the subject of many experimental studies. Several works (Lesage et al. 1981; Miller et al. 1982; Richou et al. 1984; Nick \& Helbig 1986; Pittman \& Konjević 1986; Vitel \& Skowronek 1987; Manola et al. 1988; Lesage et al. 1989; Di Rocco 1990a; Di Rocco 1990b; Konjević \& Uzelac 1990b; Bertuccelli et al. 1991a; Bertuccelli et al. 1991b; Bertuccelli \& Di Rocco 1993; Gigosos et al. 1994; Djurović et al. 2006; Ćirišan et al. 2007) are devoted to investigations of singly ionized xenon, while others (Konjević \& Pittman 1987; Iriarte et al. 1997; Romeo et al. 1998; Seidel et al. 2001; Peláez et al. 2006; Ćirišan et al. 2007) deal with doubly ionized xenon. In the papers Konjević et al. (1984), Konjević \& Wiese (1990a), Konjević et al. (2002), and Lesage (2009), critical reviews of the published experimental results are given. Some theoretical studies can be found in Popović \& Dimitrijević (1996) and in Di Rocco (1990c). Investigation of ionized xenon spectra is of interest for many areas: laser physics, fusion diagnostics, collision physics, development of light sources, as well as astrophysics.

Stark broadening data are employed in stellar plasma research, their spectra examination, analysis, and modelling. They have been used for determining chemical abundance of elements from equivalent width of absorption lines, estimation of the radiative transfer through the stellar plasmas, and for opacity calculations (Dimitrijević 2003). It is obvious that stellar spectroscopy depends on a very extensive list of elements and their atomic and spectral lines broadening data. This has become particularly important with the development of high-resolution and space spectroscopy. Furthermore, development of computer simulation demands a large amount of atomic and spectroscopic data (Iglesias et al. 1990).
Generally, stars spectra are crowded with spectral lines of many different elements, mostly ionized. Among them, ionized xenon from II to VI is identified (Sharpee et al. 2007). Xe II has been identified in a great number of HgMn Stars: k Cnc, $112 \mathrm{Her}$, 46 Aql (HD 186122), 33 Gem, HR 7143, HR 7245, HR 7361, HD 175640, etc. (Whitford 1962; Bidelman 1964; Adelman 1992; Sadakane 1993; Pintado \& Adelman 1996; Adelman et al. 1996; Ryabchikova et al. 1999; Sadakane et al. 2001; Bord et al. 2003; Castelli \& Hubrig 2004; Sharpee et al. 2007; Dworetsky et al. 2008; Karakas et al. 2009). A set of available data on Xe II has enabled a recent analysis of the role of Xe II in these stars (Castelli \& Hubrig 2004; Dworetsky et al. 2008). They measured the equivalent widths of the Xe II lines to obtain the abundance of xenon and obtained an inescapable vast overabundance of xenon in HgMn stars. Xe III is interesting for astrophysics, as well. For example, it was identified in the planetary nebulae (PNe) NGC 2440, NGC 7027, IC 2501, IC 4191, (Pequignot \& Baluteau 1994; Zhang et al. 2005; Sharpee et al. 2007). The abundance of Xe has been used to analyse the nucleosynthesis process in the PNe (Zhang et al. 2005; Sharpee et al. 2007). The explanation why Stark broadening parameters are needed for abundance measurement in the star's atmosphere can be found in Lanz \& Artru (1987) and in Lanz et al. (1988).

This work has two aims. The first one is to measure the Stark parameters of low-intensity ionized xenon lines that have not been widely analysed. The second one is to complete our previous measurements (Djurović et al. 2006; Peláez et al. 2006; Ćirišan et al. 2007) and to extend the ionized xenon Stark parameters database for astrophysical applications.

Most of the papers mentioned at the beginning, devoted to Stark parameters measurements of ionized xenon, deal with high-intensity and well-defined spectral lines. In Striganov \& Sventitskii (1968) tables, maximal Xe II line intensity is 2000 
arbitrary units. There is a similar situation in NIST tables. During the measurements, we obtained 14000 as maximal line intensity. A similar situation happens with Xe III lines, only with different numbers. The maximal measured line intensity was 80000 arbitrary units. As low-intensity lines we consider the lines having intensities lower than $10 \%$ of any of these maxima. These lines can also be important for the astrophysical diagnostic purposes because strong lines are very often self-absorbed. This work is, as already mentioned, an extension of our previous works (Djurović et al. 2006; Peláez et al. 2006; Ćirišan et al. 2007). Since the shapes or positions of measured low-intensity lines are not well-defined because of their low signal-to-noise ratio, we have repeated some measurements to obtain new Stark parameters and complete our already published data. We repeated ionized xenon Stark width measurements using a spectrometer equipped with an OMA camera (optical multichannel analyzer), as well as Stark shift measurements using the same spectrometer equipped with an ICCD camera (intensified charge coupled device), which is more sensitive and has better resolution.

In this work, 25 Stark halfwidths $(F W H W)$ and 29 shifts for Xe II spectral lines, as well as 10 Stark halfwidths and 6 shifts for Xe III spectral lines, were measured. Pulsed arc plasma, containing the mixture of $95 \%$ helium and $5 \%$ xenon, was used as a plasma source in this experiment. All measurements were performed under the following plasma conditions: electron density $(0.2-1.7) \times 10^{23} \mathrm{~m}^{-3}$ and electron temperature $18000-25500 \mathrm{~K}$.

For obtaining the Stark widths, special attention was paid to both experimental and data treatment procedures. Other broadening mechanisms were taken into account, as well.

\section{Experimental}

Experimental apparatus and diagnostic methods are described elsewhere (del Val et al. 1998; Djurović et al. 2006). Here, we only give a short description. Excitation unit contains a capacitor bank of $20 \mu \mathrm{F}$, charged up to approximately $9.2 \mathrm{kV}$. The mixture of helium (95\%) and xenon (5\%) continuously flows through the discharge lamp at a pressure of $3 \mathrm{kPa}$. Under these conditions plasma emission lasts for about $300 \mathrm{~ms}$. The lamp is a cylindrical tube of Pyrex glass, $175 \mathrm{~mm}$ in length and $19 \mathrm{~mm}$ in internal diameter. The used percentage of xenon $(5 \%)$ in the mixture was low enough to ensure minimal self-absorption, but high enough to reach maximal spectral line intensity.

Spectra were recorded using a spectrometer equipped with an OMA detector. Some measurements were repeated using an ICCD camera. Exposure times were usually $5 \mu \mathrm{s}$. Spectral measurements were performed in the first order of diffraction. The spectrometer's instrumental function was estimated by introducing a laser beam $(632.85 \mathrm{~nm})$ to its entrance slit. The halfwidth of this line, approximately $12.5 \mathrm{pm}(4.1 \mathrm{pm} / \mathrm{channel})$ when using the OMA and $7 \mathrm{pm}(2.3 \mathrm{pm} / \mathrm{channel})$ in the case of the ICCD, has been taken into account as instrumental broadening.

A part of ionized xenon spectrum is shown in Fig. 1. Wavelengths are in nm, and they were taken from NIST tables. This is a good example of low-intensity lines of Xe III next to the most intensive one. For each observed instant of plasma life, five spectra of the same region were recorded. Another five spectra were recorded using a mirror placed behind the plasma tube. Results of both recordings were averaged. Comparison of these two averaged spectra was used for self-absorption checking, which was shown to be negligible for the observed lines. This checking was important for high-intensity lines, which were used for determining temperature.

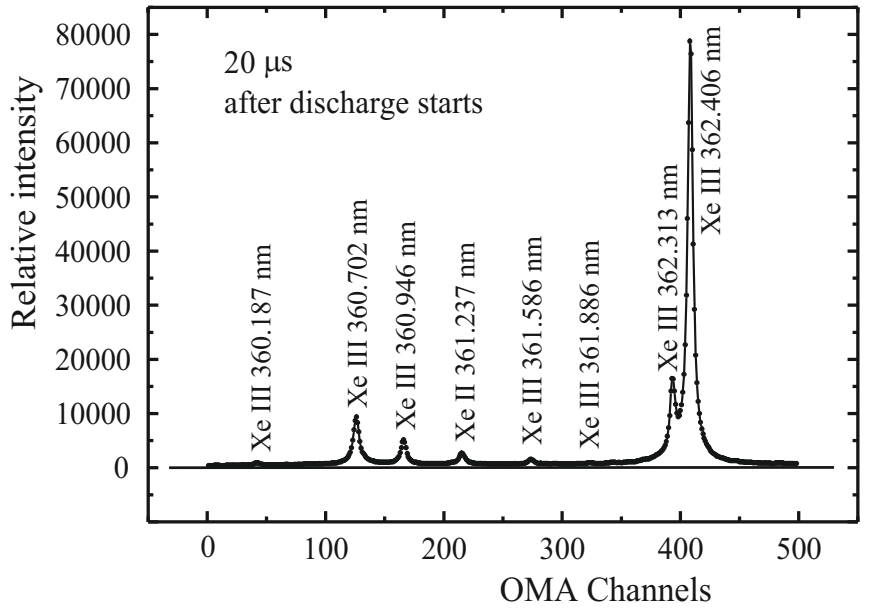

Fig. 1. Example of a part of the experimental spectrum.

An incandescent calibrated lamp and a deuterium lamp were used to obtain the spectrometer transmittance for the wavelength range 300-650 nm and for all OMA and ICCD channels. All spectra were divided by this transmittance curve, whose uncertainty was estimated to be lower than $4 \%$.

Electron density was in the range $(0.2-1.7) \times 10^{23} \mathrm{~m}^{-3}$. Twowavelengths interferometric method was used for electron density determination. This is the way to avoid the heavy particles contribution to the change of refractivity index (Aparicio et al. 1998a; de la Rosa et al. 1990). In addition, a spectroscopic method using Stark width and shift of He I $388.86 \mathrm{~nm}$ line in conjunction with Griem's (1974) theoretical model was used for checking the interferometrically obtained electron density values. The differences between spectroscopic and interferometric measurements were always lower than 15\% (Djurović et al. 2006; Peláez et al. 2006). In this work, only electron density values obtained by the interferometric method were used with an uncertainty of about $10 \%$. Results of electron density measurements for both experiments, using OMA and ICCD, are shown in Fig. 2. As seen from this figure, there are two and three electron-density maxima, respectively. The current was not critically dumped, and the dumping resistor was changed in experiment with the ICCD.

Electron temperature was determined by a Botzmann-plot of $24 \mathrm{Xe}$ II lines, and it was in the range (18000-25500 K). Estimated uncertainties are about $15 \%$. Results of electron temperature measurements for both experiments are shown in Fig. 3. The comment on electron temperature maxima is the same as for electron density maxima.

\section{Data treatment}

The experimental data treatment is explained in detail in our previous work (Djurović et al. 2006). Here, only a short description will be given. A fitting procedure (Gigosos et al. 1994) was applied to the experimentally obtained spectrum to determine the total line width, the central position and the area of each spectral line profile. The spectra were fitted to the sum of asymmetrical Lorentzian functions that represent the spectral line profiles and a linear function, which represent the emission from continuum. The influence of the adjustment on the final results, both fitting parameters and the algorithm, has been found to be less than experimental errors (Bayón et al. 1994). 


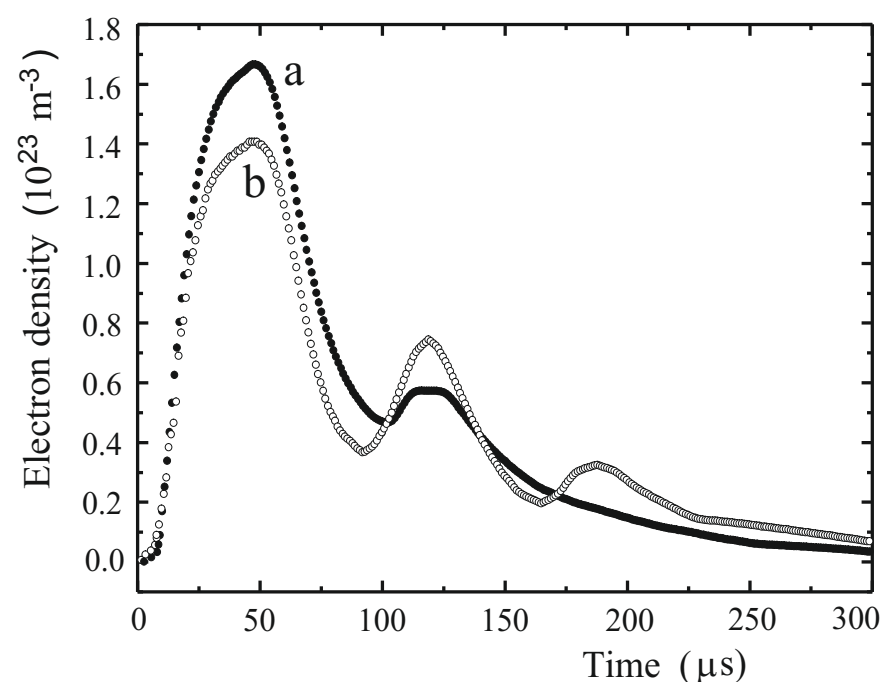

Fig. 2. Results of interferometric electron density measurements in OMA experiment (a-full points) and ICCD experiment (b-open points).

To obtain Stark halfwidth from the total experimental halfwidth of the spectral line, a standard deconvolution procedure was used (Davies \& Vaughan 1963). Other broadening mechanisms were also taken into account. Doppler width was small, lower than $7 \mathrm{pm}$, due to the great weight of the emitting ions. Van der Waals broadening was about $0.43 \mathrm{pm}$ at $T=20000 \mathrm{~K}$ (Griem 1964). Resonance broadening was about $0.2 \mathrm{pm}$ (Griem 1964), and ionic broadening was always lower than $1 \mathrm{pm}$ (Griem 1974). It is obvious that van der Waals and resonance broadening were negligibly small for the plasma conditions in this experiment, so these mechanisms were not considered in the final calculations. In the deconvolution procedure (Davies \& Vaughan 1963), total Gaussian width component (instrumental + doppler) and Lorentzian Stark width component were taken into account.

Stark shifts were obtained using a method described in Aparicio (1998b). First, it was assumed that there is no Stark shift when electron density $N_{\mathrm{e}}=0$. Since the exact position of an observed spectral line at $N_{\mathrm{e}}=0$ is unknown, this value was obtained by extrapolating the linear fit of the lines centre positions versus electron density to zero electron density. Once this value was subtracted from the measured lines centre positions, the resulting differences multiplied by the inverse linear dispersion of the spectroscopic system gave us the desired Stark shift values (in pm).

\section{Results and discussion}

\subsection{Xe II width results}

The Stark halfwidth results of 25 Xe II spectral lines from 21 multiplet are given in Table 1 . The first four columns give the multiplet number, configurations, terms and wavelengths of the lines. The multiplets are arranged in the same way as in the NIST atomic spectra database. In the fifth column, measured halfwidths $\left(w_{\mathrm{m}}\right)$ and corresponding estimated accuracies (Acc) are given, while the sixth column contains measured halfwidths expressed in angular frequency units. The measured data are classified according to the experimental accuracy estimation as $\mathrm{A} \leq 15 \%, \mathrm{~B} \leq 25 \%, \mathrm{C} \leq 35 \%$. All data correspond to an electron density of $N_{\mathrm{e}}=10^{23} \mathrm{~m}^{-3}$ and electron temperature of $T_{\mathrm{e}}=22000 \mathrm{~K}$. The seventh column contains the

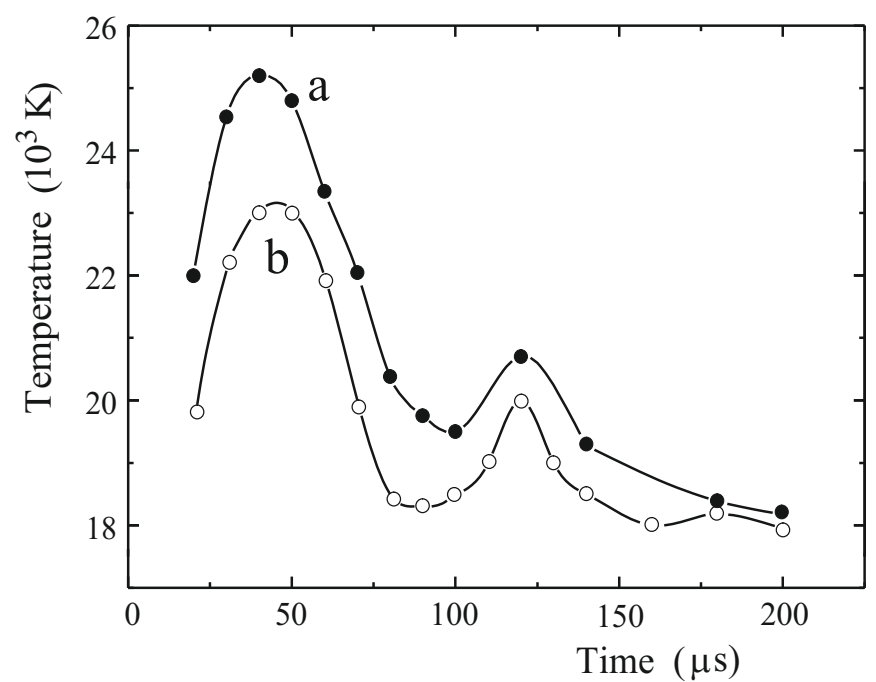

Fig. 3. Temporal evolution of the electron temperature in OMA experiment (a-full points) and ICCD experiment (b-open points).

comparison between the experimentally obtained halfwidth values and theoretical ones $\left(w_{\text {calc }}\right)$ calculated by modified semiempirical formula (Dimitrijević \& Konjević 1980). The last two columns contain the experimental data of other authors $(w)$, Stark halfwidths, and references. Experimental halfwidth data of these authors (Pittman \& Konjević 1986-PK; Lesage et al. 1989-LAM; Bertuccelli et al. 1991a-BBDa; Bertuccelli et al. 1991b-BBDb; Gigosos et al. 1994-GMPR), have been scaled to $N_{\mathrm{e}}=10^{23} \mathrm{~m}^{-3}$ and $T_{\mathrm{e}}=22000 \mathrm{~K}$ using the $T^{-1 / 2}$ dependence.

All measured halfwidths show linear dependence on electron density. Since here we deal with low-intensity spectral lines, estimated accuracy of the Stark parameters depends on several aspects. The most important is the shape of the experimental line profile. The best accuracy $(\mathrm{A} \leq 15 \%)$ was obtained for the wellisolated lines. Figure 4 shows an example of halfwidth vs. electron density plot given for Xe II $444.813 \mathrm{~nm}$ line, as well as its corresponding experimental profile.

Lower accuracy of Stark parameters (B $\leq 25 \%)$ was obtained in cases where the line profile of interest was still well-defined in spite of the closeness of other neighbouring lines. Figure 5 shows an example of halfwidth vs. electron density plot for Xe II $467.456 \mathrm{~nm}$ line, as well as its corresponding experimental profile.

The lowest Stark parameters accuracy $(\mathrm{C} \leq 35 \%)$ was obtained in cases where the neighbouring lines appear too close to the line profile of interest. Figure 6 shows an example of halfwidth vs. electron density plot for Xe II $384.858 \mathrm{~nm}$ line, as well as its corresponding experimental profile. An appropriate fitting procedure (Gigosos et al. 1994) was applied to resolve the profile of Xe II $384.858 \mathrm{~nm}$ line from the neighbouring Xe II $384.987 \mathrm{~nm}$ line. Even in these cases, linear electron density dependences of Stark halfwidths are preserved.

There are not many cases for intra-multiplet analysis of Stark halfwidth behaviour. Only four multiplets, 1, 8, 9, and 11, contain measured Stark data for two lines. If we take the experimental error into account, we can say that the results are in good agreement with Stark halfwidth regularity within the multiplet. The difference between halfwidth results should be within several percent, as predicted by Wiese \& Konjević (1982). For this comparison, halfwidth values were converted to angular frequency units in order to avoid the influence of wavelength (sixth column in Table 1). 
Table 1. Experimental Stark halfwidths of Xe II lines.

\begin{tabular}{|c|c|c|c|c|c|c|c|c|}
\hline No. & Configurations & Terms & $\begin{array}{l}\text { Wavelength } \\
\quad(\mathrm{nm})\end{array}$ & $\begin{array}{r}w_{\mathrm{m}} \mathrm{Acc} \\
(\mathrm{pm})\end{array}$ & $\left(\begin{array}{r}w_{\mathrm{m}} \\
\left(10^{11} \mathrm{~s}^{-1}\right)\end{array}\right.$ & $w_{\mathrm{m}} / w_{\text {calc }}$ & $\begin{array}{r}w \\
(\mathrm{pm})\end{array}$ & Ref. \\
\hline \multirow[t]{2}{*}{1.} & $5 p^{4}\left({ }^{3} P_{2}\right) 6 s-5 p^{4}\left({ }^{3} P_{1}\right) 6 p$ & {$[2]_{5 / 2}-[2]_{5 / 2}^{\mathrm{o}}$} & 332.746 & $22.1 \mathrm{~A}$ & 3.76 & 1.18 & & \\
\hline & & {$[2]_{3 / 2}-[2]_{5 / 2}^{\mathrm{o}}$} & 356.430 & $26.9 \mathrm{~B}$ & 3.99 & 1.26 & & \\
\hline 2. & $5 p^{4}\left({ }^{3} P_{2}\right) 5 d-5 p^{4}\left({ }^{3} P_{2}\right) 6 p$ & {$[2]_{5 / 2}-[1]_{3 / 2}^{o}$} & 467.456 & $47.7 \mathrm{~B}$ & 4.11 & & & \\
\hline 3. & $5 p^{4}\left({ }^{3} P_{1}\right) 5 d-5 p^{4}\left({ }^{3} P_{1}\right) 6 p$ & {$[1]_{3 / 2}-[2]_{3 / 2}^{\mathrm{o}}$} & 651.283 & $98.4 \mathrm{~A}$ & 4.37 & & & \\
\hline 4. & $5 \mathrm{p}^{4}\left({ }^{3} \mathrm{P}_{2}\right) 5 \mathrm{~d}-5 \mathrm{p}^{4}\left({ }^{3} \mathrm{P}_{1}\right) 6 \mathrm{p}$ & {$[0]_{1 / 2}-[1]_{1 / 2}^{o}$} & 536.807 & $53.6 \mathrm{~B}$ & 3.50 & & $\begin{array}{l}38.85 \\
69.24\end{array}$ & $\begin{array}{l}\text { BBDa } \\
\text { GMPR }\end{array}$ \\
\hline 5. & $5 p^{4}\left({ }^{3} P_{2}\right) 5 d-5 p^{4}\left({ }^{1} D_{2}\right) 6 p$ & {$[0]_{1 / 2}-[2]_{3 / 2}^{\mathrm{o}}$} & 384.858 & $22.4 \mathrm{C}$ & 2.85 & & & \\
\hline 6. & $5 p^{4}\left({ }^{3} P_{0}\right) 5 d-5 p^{4}\left({ }^{1} D_{2}\right) 6 p$ & {$[2]_{5 / 2}-[3]_{7 / 2}^{o}$} & 453.249 & $33.9 \mathrm{~B}$ & 3.11 & & 38.89 & LAM \\
\hline 7. & $5 \mathrm{p}^{4}\left({ }^{3} \mathrm{P}_{0}\right) 5 \mathrm{~d}-5 \mathrm{p}^{4}\left({ }^{1} \mathrm{D}_{2}\right) 6 \mathrm{p}$ & {$[2]_{5 / 2}-[2]_{5 / 2}^{\mathrm{o}}$} & 413.101 & $48.6 \mathrm{~B}$ & 5.37 & & & \\
\hline \multirow[t]{2}{*}{8.} & $5 p^{4}\left({ }^{3} P_{0}\right) 5 d-5 p^{4}\left({ }^{3} P_{2}\right) 4 f$ & {$[2]_{5 / 2}-[2]_{5 / 2}^{\mathrm{o}}$} & 310.440 & $59.7 \mathrm{~B}$ & 11.67 & & & \\
\hline & & {$[2]_{3 / 2}-[2]_{3 / 2}^{\mathrm{o}}$} & 311.274 & $56.5 \mathrm{~B}$ & 10.99 & & & \\
\hline \multirow[t]{2}{*}{9.} & $5 p^{4}\left({ }^{1} D_{2}\right) 6 s-5 p^{4}\left({ }^{1} D_{2}\right) 6 p$ & {$[2]_{3 / 2}-[1]_{1 / 2}^{\mathrm{o}}$} & 504.492 & $61.4 \mathrm{~A}$ & 4.55 & 1.35 & $\begin{array}{l}51.46 \\
61.93\end{array}$ & $\begin{array}{l}\text { BBDa } \\
\text { BBDb }\end{array}$ \\
\hline & & {$[2]_{3 / 2}-[1]_{3 / 2}^{\mathrm{o}}$} & 597.113 & $75.1 \mathrm{~A}$ & 3.97 & 1.49 & & \\
\hline 10. & $5 p^{4}\left({ }^{3} P_{1}\right) 5 d-5 p^{4}\left({ }^{3} P_{2}\right) 4 f$ & {$[2]_{3 / 2}-[2]_{5 / 2}^{\mathrm{o}}$} & 346.126 & $81.3 \mathrm{~A}$ & 12.79 & & & \\
\hline \multirow[t]{2}{*}{11.} & $5 p^{4}\left({ }^{3} P_{2}\right) 6 p-5 p^{4}\left({ }^{3} P_{2}\right) 6 d$ & {$[1]_{1 / 2}^{\mathrm{o}}-[1]_{3 / 2}$} & 384.987 & $164.7 \mathrm{~A}$ & 20.94 & & & \\
\hline & & {$[1]_{3 / 2}^{\mathrm{o}}-[1]_{3 / 2}$} & 437.378 & $193.9 \mathrm{~A}$ & 19.10 & & & \\
\hline 12. & $5 p^{4}\left({ }^{1} D_{2}\right) 5 d-5 p^{4}\left({ }^{3} P_{2}\right) 4 f$ & {$[3]_{5 / 2}-[4]_{7 / 2}^{\mathrm{o}}$} & 477.319 & $121.8 \mathrm{~B}$ & 10.07 & & & \\
\hline 13. & $5 p^{4}\left({ }^{3} P_{0}\right) 6 p-5 p^{4}\left({ }^{3} P_{1}\right) 6 d$ & {$[1]_{3 / 2}^{\mathrm{o}}-[2]_{3 / 2}$} & 411.214 & $111.9 \mathrm{~B}$ & 12.47 & & & \\
\hline 14. & $5 p^{4}\left({ }^{3} P_{1}\right) 6 p-5 p^{4}\left({ }^{3} P_{1}\right) 7 s$ & {$[0]_{1 / 2}^{\mathrm{o}}-[1]_{3 / 2}$} & 471.518 & $185.3 \mathrm{C}$ & 15.70 & & & \\
\hline 15. & $5 p^{4}\left({ }^{3} P_{1}\right) 6 p-5 p^{4}\left({ }^{3} P_{1}\right) 6 d$ & {$[2]_{5 / 2}^{\mathrm{o}}-[3]_{7 / 2}$} & 444.813 & $146.2 \mathrm{~A}$ & 13.92 & & 93.34 & LAM \\
\hline 16. & $5 p^{4}\left({ }^{3} P_{1}\right) 6 p-5 p^{4}\left({ }^{3} P_{1}\right) 6 d$ & {$[2]_{3 / 2}^{o}-[2]_{3 / 2}$} & 440.688 & $139.1 \mathrm{~B}$ & 13.49 & & 151.12 & PK \\
\hline 17. & $5 p^{4}\left({ }^{1} D_{2}\right) 5 d-5 p^{4}\left({ }^{1} D_{2}\right) 4 f$ & {$[1]_{3 / 2}-[2]_{3 / 2}^{\mathrm{o}}$} & 310.151 & $67.8 \mathrm{~B}$ & 13.28 & & & \\
\hline 18. & $5 p^{4}\left({ }^{3} P_{1}\right) 6 p-5 p^{4}\left({ }^{3} P_{1}\right) 7 s$ & {$[1]_{1 / 2}^{o}-[1]_{1 / 2}$} & 544.545 & $122.8 \mathrm{~A}$ & 7.80 & & & \\
\hline 19. & $5 p^{4}\left({ }^{1} D_{2}\right) 5 d-5 p^{4}\left({ }^{3} P_{1}\right) 4 f$ & {$[2]_{5 / 2}-[4]_{7 / 2}^{o}$} & 400.235 & $168.1 \mathrm{~B}$ & 19.77 & & & \\
\hline 20. & $5 \mathrm{p}^{4}\left({ }^{1} \mathrm{D}_{2}\right) 5 \mathrm{~d}-5 \mathrm{p}^{4}\left({ }^{3} \mathrm{P}_{1}\right) 4 \mathrm{f}$ & {$[2]_{5 / 2}-[3]_{7 / 2}^{\mathrm{o}}$} & 393.892 & $150.8 \mathrm{~B}$ & 18.31 & & & \\
\hline 21. & $5 p^{4}\left({ }^{1} D_{2}\right) 6 p-5 p^{4}\left({ }^{1} D_{2}\right) 7 s$ & {$[1]_{3 / 2}^{\mathrm{o}}-[2]_{5 / 2}$} & 499.117 & $186.6 \mathrm{C}$ & 14.11 & & 172.60 & GMPR \\
\hline
\end{tabular}

Comparison of present results and theoretical data calculated using modified semiempirical formula (Dimitrijević \& Konjević 1980) $\left(w_{\mathrm{m}} / w_{\text {calc }}\right)$ is given for two multiplets, 1 and 9 . The calculations were performed only in the cases for which complete set of perturbing levels, necessary for modified semiempirical calculations (Dimitrijević \& Konjević 1980), was available in NIST data. For these calculations, a $j K$ coupling scheme, which is appropriate for Xe II (Hansen \& Persson 1987), was used. The ratio between measured and calculated halfwidths is between 1.2 and 1.5, which can be considered as good agreement. This is often the case for Stark halfwidths of Xe II lines (Djurović et al. 2006).

Experimental results of other authors (Pittman \& Konjević 1986; Lesage et al. 1989; Bertuccelli et al. 1991a; Bertuccelli et al. 1991b; Gigosos et al. 1994) are given in the eighth column of Table 1 . The ratios $w_{\mathrm{m}} / w$ for most of the lines are between 0.8 and 1.2 , for all references. There are only two exceptions: line $536.807 \mathrm{~nm}$ in multiplet 4 (Bertuccelli et al. 1991a) and line $444.813 \mathrm{~nm}$ in multiplet 15 (Lesage et al. 1989) with the ratios of about 1.4 and 1.6, respectively. At the same time, the ratio $w_{\mathrm{m}} / w$ (Gigosos et al. 1994) for $536.807 \mathrm{~nm}$ line is 0.8 . Here it is necessary to mention that for the $536.807 \mathrm{~nm}$ line, electron density was estimated, in the paper of Bertuccelli et al. (1991a), by comparing the experimental widths of three Xe II lines with those obtained in Miller et al. (1982), Richou et al. (1984), Vitel \& Skowronek (1987), and Lesage et al. (1989). Furthermore, two of those lines were photographically recorded. The $444.813 \mathrm{~nm}$ line in Lesage et al. (1989) was also photographically recorded, while electron density was measured from the $\mathrm{H}_{\beta}$ Balmer line.
Photographic technique and methods of electron density measurements could explain the observed discrepancy.

Generally, if experimental errors are taken into account, present and other experimental results are in good agreement. For this comparison, all other authors' halfwidth results (Pittman \& Konjević 1986; Lesage et al. 1989; Bertuccelli et al. 1991a, 1991b; Gigosos et al. 1994) have been scaled to $T_{\mathrm{e}}=22000 \mathrm{~K}$, as shown in eighth column of Table 1.

Only for Xe II $504.492 \mathrm{~nm}$ line in multiplet 9, Table 1, are there simultaneously available present data, theoretical calculations (Dimitrijević \& Konjević 1980) and other experimental halfwidth results (Bertuccelli et al. 1991a, 1991b). This enables us to analyse its temperature dependence, as shown in Fig. 7.

\subsection{Xe II shift results}

Stark shift results of 29 Xe II spectral lines from 26 multiplets are given in Table 2. The table is organized in the same way as Table 1. The seventh column contains the comparison of experimental shift values $\left(d_{\mathrm{m}}\right)$ with the theoretical ones $\left(d_{\text {calc }}\right)$, calculated by a modified semiempirical formula (Dimitrijević \& Kršljanin 1986). Only one experimental result of other authors (d) is available (Gigosos et al. 1994-GMPR) for the comparison with the present results.

The procedures for checking electron density dependence and estimating experimental errors, described in the previous section, were also employed in the case of Stark shifts. Stark shift intra-multiplet regularity checking is possible for multiplets 3,4 , and 21 . The shift differences are within $\pm 10 \%$, as 
Table 2. Experimental Stark shifts of Xe II lines.

\begin{tabular}{|c|c|c|c|c|c|c|c|c|}
\hline No. & Configurations & Terms & $\begin{array}{l}\text { Wavelength } \\
(\mathrm{nm})\end{array}$ & $\begin{array}{r}d_{\mathrm{m}} \text { Acc } \\
(\mathrm{pm}) \\
\end{array}$ & $\begin{array}{r}d_{\mathrm{m}} \\
\left(10^{11} \mathrm{~s}^{-1}\right) \\
\end{array}$ & $d_{\mathrm{m}} / d_{\mathrm{calc}}$ & $\begin{array}{r}d \\
(\mathrm{pm})\end{array}$ & Ref. \\
\hline 1. & $5 s 5 p^{6}-5 p^{4}\left({ }^{3} P_{2}\right) 6 p$ & ${ }^{2} \mathrm{~S}_{1 / 2}-[2]_{3 / 2}^{0}$ & 477.918 & $6.7 \mathrm{~A}$ & -5.53 & & & \\
\hline 2. & $5 s 5 p^{6}-5 p^{4}\left({ }^{3} P_{2}\right) 6 p$ & ${ }^{2} S_{1 / 2}-[1]_{1 / 2}^{o}$ & 438.493 & $7.2 \mathrm{~B}$ & -7.05 & & & \\
\hline \multirow[t]{2}{*}{3.} & $5 p^{4}\left({ }^{3} \mathrm{P}_{2}\right) 6 s-5 p^{4}\left({ }^{3} \mathrm{P}_{1}\right) 6 \mathrm{p}$ & {$[2]_{5 / 2}-[2]_{5 / 2}^{0}$} & 332.746 & $-3.2 \mathrm{~B}$ & 5.45 & 0.62 & & \\
\hline & & {$[2]_{3 / 2}-[2]_{5 / 2}^{\mathrm{o}}$} & 356.430 & $-4.0 \mathrm{~A}$ & 5.93 & 0.58 & & \\
\hline \multirow[t]{2}{*}{4.} & $5 p^{4}\left({ }^{3} P_{2}\right) 5 d-5 p^{4}\left({ }^{3} P_{2}\right) 6 p$ & {$[2]_{5 / 2}-[1]_{3 / 2}^{o}$} & 467.456 & $5.8 \mathrm{~B}$ & -5.00 & & & \\
\hline & & {$[2]_{3 / 2}-[1]_{3 / 2}^{0}$} & 481.802 & $5.7 \mathrm{C}$ & -4.62 & & & \\
\hline 5. & $5 p^{4}\left({ }^{3} P_{2}\right) 5 d-5 p^{4}\left({ }^{3} P_{0}\right) 6 p$ & {$[2]_{3 / 2}-[1]_{1 / 2}^{o}$} & 410.034 & $-1.0 \mathrm{C}$ & 1.12 & & & \\
\hline 6. & $5 p^{4}\left({ }^{3} P_{2}\right) 5 d-5 p^{4}\left({ }^{3} P_{1}\right) 6 p$ & {$[3]_{7 / 2}-[2]_{5 / 2}^{o}$} & 361.237 & $|d|<1$ & & & & \\
\hline 7. & $5 \mathrm{p}^{4}\left({ }^{3} \mathrm{P}_{2}\right) 5 \mathrm{~d}-5 \mathrm{p}^{4}\left({ }^{1} \mathrm{D}_{2}\right) 6 \mathrm{p}$ & {$[1]_{3 / 2}-[3]_{5 / 2}^{o}$} & 424.441 & $-7.1 \mathrm{C}$ & 7.43 & & & \\
\hline 8. & $5 \mathrm{p}^{4}\left({ }^{3} \mathrm{P}_{2}\right) 5 \mathrm{~d}-5 \mathrm{p}^{4}\left({ }^{1} \mathrm{D}_{2}\right) 6 \mathrm{p}$ & {$[1]_{3 / 2}-[1]_{3 / 2}^{0}$} & 410.495 & $-0.9 \mathrm{C}$ & 1.01 & & & \\
\hline 9. & $5 \mathrm{p}^{4}\left({ }^{3} \mathrm{P}_{2}\right) 5 \mathrm{~d}-5 \mathrm{p}^{4}\left({ }^{1} \mathrm{D}_{2}\right) 6 \mathrm{p}$ & {$[4]_{7 / 2}-[3]_{5 / 2}^{0}$} & 365.774 & $-2.0 \mathrm{C}$ & 2.82 & & & \\
\hline 10. & $5 p^{4}\left({ }^{3} P_{0}\right) 6 s-5 p^{4}\left({ }^{3} P_{1}\right) 6 p$ & {$[0]_{1 / 2}-[1]_{1 / 2}^{\mathrm{o}}$} & 426.984 & $-5.4 \mathrm{~B}$ & 5.58 & 0.63 & & \\
\hline 11. & $5 p^{4}\left({ }^{3} P_{0}\right) 6 s-5 p^{4}\left({ }^{1} D_{2}\right) 6 p$ & {$[0]_{1 / 2}-[1]_{1 / 2}^{0}$} & 316.527 & $-4.2 \mathrm{C}$ & 7.90 & 0.89 & & \\
\hline 12. & $5 \mathrm{p}^{4}\left({ }^{3} \mathrm{P}_{1}\right) 5 \mathrm{~d}-5 \mathrm{p}^{4}\left({ }^{1} \mathrm{D}_{2}\right) 6 \mathrm{p}$ & {$[1]_{3 / 2}-[1]_{1 / 2}^{o}$} & 402.519 & $3.9 \mathrm{C}$ & -4.53 & & & \\
\hline 13. & $5 p^{4}\left({ }^{3} P_{1}\right) 5 d-5 p^{4}\left({ }^{1} D_{2}\right) 6 p$ & {$[1]_{3 / 2}-[2]_{3 / 2}^{0}$} & 416.216 & $7.1 \mathrm{~B}$ & -7.72 & & & \\
\hline 14. & $5 \mathrm{p}^{4}\left({ }^{3} \mathrm{P}_{2}\right) 5 \mathrm{~d}-5 \mathrm{p}^{4}\left({ }^{1} \mathrm{D}_{2}\right) 6 \mathrm{p}$ & {$[0]_{1 / 2}-[1]_{1 / 2}^{\mathrm{o}}$} & 373.118 & $|d|<1$ & & & & \\
\hline 15. & $5 p^{4}\left({ }^{3} P_{0}\right) 5 d-5 p^{4}\left({ }^{1} D_{2}\right) 6 p$ & {$[2]_{5 / 2}-[3]_{7 / 2}^{0}$} & 453.249 & $-2.8 \mathrm{~B}$ & 2.57 & & & \\
\hline 16. & $5 p^{4}\left({ }^{3} P_{0}\right) 5 d-5 p^{4}\left({ }^{3} P_{2}\right) 7 p$ & {$[2]_{3 / 2}-[2]_{5 / 2}^{0}$} & 314.899 & $-11.7 \mathrm{C}$ & 2.22 & & & \\
\hline 17. & $5 p^{4}\left({ }^{3} P_{1}\right) 5 d-5 p^{4}\left({ }^{3} P_{2}\right) 4 f$ & {$[3]_{7 / 2}-[2]_{5 / 2}^{o}$} & 314.502 & $|d|<1$ & & & & \\
\hline 18. & $5 p^{4}\left({ }^{1} D_{2}\right) 6 s-5 p^{4}\left({ }^{3} P_{2}\right) 7 p$ & {$[2]_{5 / 2}-[1]_{3 / 2}^{\mathrm{o}}$} & 337.392 & $-18.6 \mathrm{C}$ & 30.78 & & & \\
\hline 19. & $5 p^{4}\left({ }^{1} D_{2}\right) 6 s-5 p^{4}\left({ }^{3} P_{2}\right) 7 p$ & {$[2]_{5 / 2}-[3]_{7 / 2}^{0}$} & 331.348 & $-11.4 \mathrm{C}$ & 19.56 & & & \\
\hline 20. & $5 p^{4}\left({ }^{3} P_{1}\right) 5 d-5 p^{4}\left({ }^{3} P_{2}\right) 7 p$ & {$[2]_{5 / 2}-[2]_{5 / 2}^{0}$} & 378.323 & $-9.1 \mathrm{C}$ & 11.98 & & & \\
\hline \multirow[t]{2}{*}{21.} & $5 p^{4}\left({ }^{3} P_{2}\right) 6 p-5 p^{4}\left({ }^{3} P_{2}\right) 7 s$ & {$[2]_{3 / 2}^{\mathrm{o}}-[2]_{5 / 2}$} & 482.335 & $57.5 \mathrm{~B}$ & -46.56 & 1.49 & & \\
\hline & & {$[2]_{5 / 2}^{\mathrm{o}}-[2]_{5 / 2}$} & 486.245 & $55.2 \mathrm{~A}$ & -43.99 & 1.41 & 47.07 & GMPR \\
\hline 22. & $5 p^{4}\left({ }^{3} P_{2}\right) 6 p-5 p^{4}\left({ }^{3} P_{2}\right) 6 d$ & {$[2]_{3 / 2}^{\mathrm{o}}-[3]_{5 / 2}$} & 366.170 & $53.5 \mathrm{~A}$ & -75.17 & & & \\
\hline 23. & $5 p^{4}\left({ }^{3} P_{2}\right) 6 p-5 p^{4}\left({ }^{3} P_{0}\right) 6 d$ & {$[1]_{1 / 2}^{\mathrm{o}}-[2]_{3 / 2}$} & 328.126 & $26.9 \mathrm{~A}$ & -47.07 & & & \\
\hline 24. & $5 p^{4}\left({ }^{3} P_{2}\right) 6 p-5 p^{4}\left({ }^{3} P_{1}\right) 6 d$ & {$[1]_{3 / 2}^{0}-[2]_{5 / 2}$} & 338.630 & $28.5 \mathrm{~A}$ & -46.82 & & & \\
\hline 25. & $5 p^{4}\left({ }^{3} P_{0}\right) 6 p-5 p^{4}\left({ }^{3} P_{1}\right) 7 s$ & {$[1]_{3 / 2}^{\mathrm{o}}-[1]_{1 / 2}$} & 469.334 & $53.2 \mathrm{~B}$ & -45.50 & & & \\
\hline 26. & $5 p^{4}\left({ }^{3} P_{1}\right) 6 p-5 p^{4}\left({ }^{3} P_{1}\right) 6 d$ & {$[1]_{3 / 2}^{0}-[1]_{1 / 2}$} & 477.576 & $7.1 \mathrm{C}$ & -5.86 & & & \\
\hline
\end{tabular}

predicted in Wiese \& Konjević (1992). For this comparison, shift values were converted to angular frequency units (sixth column in Table 2).

Some measured shifts are particularly low, close to the limit of measurement precision. This is the case for the lines from multiplets 6, 14, and 17. In these cases, experimental errors represent a significant percentage of the measured Stark shifts, so only estimations are given in Table 2.

Comparison of measured Stark shifts with theoretical data calculated using modified semiempirical formula (Dimitrijević \& Kršljanin 1986) $\left(d_{\mathrm{m}} / d_{\text {calc }}\right)$ is given for multiplets $3,10,11$, and 21. The calculations were performed only in cases for which complete sets of perturbing levels, necessary for modified semiempirical calculations (Dimitrijević \& Kršljanin 1986), were available in NIST data. For these calculations, a $j K$ coupling scheme was used. The ratio between measured and calculated shifts ranges between 0.6 and 1.5 , which can be considered as good agreement for shifts (Popović \& Dimitrijević 1996).

As already mentioned, only one experimental result (Gigosos et al. 1994) is available for comparison with present results. It corresponds to the $486.245 \mathrm{~nm}$ line from multiplet 21 . The agreement is very good, i.e., the ratio is $d_{\mathrm{m}} / d=1.17$. The shift result from Gigosos et al. (1994) has also been scaled to $T_{\mathrm{e}}=22000 \mathrm{~K}$ (eighth column in Table 2).

Here, we should make a comment on the multiplet classification of the $328.126 \mathrm{~nm}$ line in multiplet 23. According to the NIST database, there are two lines with the same wavelength and relative intensity: one is classified as in the Table $2,5 \mathrm{p}^{4}\left({ }^{3} \mathrm{P}_{2}\right)$ $6 \mathrm{p}[1]^{\mathrm{o}}{ }_{1 / 2}-5 \mathrm{p}^{4}\left({ }^{3} \mathrm{P}_{0}\right) 6 \mathrm{~d}[2]_{3 / 2}$, while the other one is classified as $5 \mathrm{p}^{4}\left({ }^{1} \mathrm{D}_{2}\right)$ 6s $[2]_{5 / 2}-5 \mathrm{p}^{4}\left({ }^{3} \mathrm{P}_{2}\right)$ 4f $[4]^{\circ} 7 / 2$. In the Striganov \& Sventitskii (1968) tables, $L S$ coupling scheme is used and line $328.126 \mathrm{~nm}$ is classified as $6 \mathrm{p}^{4} \mathrm{P}_{1 / 2}^{\mathrm{o}}-6 \mathrm{~d}^{4} \mathrm{P}_{3 / 2}$, i.e., with the same transition $6 \mathrm{p}-6 \mathrm{~d}$ as in the first case of NIST classification. This is the reason for the classification we used in Table 2.

\subsection{Xe III width results}

Stark width results of $10 \mathrm{Xe}$ III spectral lines from 8 multiplets are given in Table 3. The table is organized in the same way as Table 1. The seventh column contains the comparison between experimental halfwidth values $\left(w_{\mathrm{m}}\right)$ and theoretical ones $\left(w_{\text {calc }}\right)$, calculated by modified semiempirical formula (Dimitrijević \& Konjević 1980). The present results are also compared with experimental data of other authors $(w)$ (Konjević \& Pittman 1987-KP; Iriarte et al. 1997-IRBD; Romeo et al. 1998-RIBD).

The halfwidth's linear dependence on electron density is satisfied for all investigated lines. Intra-multiplet regularity can be checked only in two cases, multiplets 2 and 6 . The difference between the measured halfwidths in multiplet 2 is about $1 \%$, while in multiplet 6 it is less than $4 \%$. This is in good agreement with the regularity established by Wiese \& Konjević (1982).

Comparison of the present halfwidths with the theoretical ones, calculated using modified semiempirical formula 
Table 3. Experimental Stark halfwidths of Xe III lines.

\begin{tabular}{|c|c|c|c|c|c|c|c|c|}
\hline No. & Configurations & Terms & $\begin{array}{l}\text { Wavelength } \\
(\mathrm{nm})\end{array}$ & $\begin{array}{r}w_{\mathrm{m}} \text { Acc } \\
(\mathrm{pm})\end{array}$ & $\begin{array}{r}w_{\mathrm{m}} \\
\left(10^{11} \mathrm{~s}^{-1}\right)\end{array}$ & $w_{\mathrm{m}} / w_{\text {calc }}$ & $\begin{array}{r}w \\
(\mathrm{pm})\end{array}$ & Ref. \\
\hline 1. & $\left({ }^{2} \mathrm{D}^{\mathrm{o}}\right) 5 \mathrm{~d}-\left({ }^{2} \mathrm{D}^{\mathrm{o}}\right) 6 \mathrm{p}$ & ${ }^{3} \mathrm{~F}_{4}^{\mathrm{o}}-{ }^{3} \mathrm{~F}_{3}$ & 308.353 & $15.4 \mathrm{~B}$ & 3.05 & & 36.84 & RIBD \\
\hline \multirow[t]{2}{*}{2.} & $\left({ }^{2} D^{o}\right) 6 s-\left({ }^{4} S^{o}\right) 4 f$ & ${ }^{3} \mathrm{D}_{3}^{\mathrm{o}}-{ }^{5} \mathrm{~F}_{3}$ & 360.702 & $17.0 \mathrm{~B}$ & 2.46 & & $\begin{array}{l}18.17 \\
36.72\end{array}$ & $\begin{array}{r}\text { KP } \\
\text { RIBD }\end{array}$ \\
\hline & & ${ }^{3} \mathrm{D}_{3}^{\mathrm{o}}-{ }^{5} \mathrm{~F}_{4}$ & 360.946 & $17.2 \mathrm{~B}$ & 2.49 & & & \\
\hline 3. & $\left({ }^{2} \mathrm{P}^{\mathrm{o}}\right) 5 \mathrm{~d}-\left({ }^{4} \mathrm{~S}^{\mathrm{o}}\right) 4 \mathrm{f}$ & ${ }^{1} \mathrm{D}_{2}^{\mathrm{o}}-{ }^{5} \mathrm{~F}_{3}$ & 333.165 & $18.4 \mathrm{~A}$ & 3.12 & & 29.74 & RIBD \\
\hline 4. & $\left({ }^{2} \mathrm{P}^{\mathrm{o}}\right) 5 \mathrm{~d}-\left({ }^{2} \mathrm{D}^{\mathrm{o}}\right) 6 \mathrm{p}$ & ${ }^{3} \mathrm{P}_{1}^{\mathrm{o}}-{ }^{3} \mathrm{P}_{1}$ & 365.461 & $21.2 \mathrm{~B}$ & 2.99 & & 28.12 & RIBD \\
\hline 5. & $\left({ }^{2} \mathrm{D}^{\mathrm{o}}\right) 6 \mathrm{~s}-\left({ }^{2} \mathrm{D}^{\mathrm{o}}\right) 6 \mathrm{p}$ & ${ }^{1} \mathrm{D}_{2}^{\mathrm{o}}-{ }^{1} \mathrm{~F}_{3}$ & 467.367 & $36.1 \mathrm{~B}$ & 3.11 & 0.77 & 41.45 & IRBD \\
\hline \multirow[t]{2}{*}{6.} & $\left({ }^{2} \mathrm{P}^{\mathrm{o}}\right) 6 \mathrm{~s}-\left({ }^{2} \mathrm{P}^{\mathrm{o}}\right) 6 \mathrm{p}$ & ${ }^{3} \mathrm{P}_{0}^{\mathrm{o}}-{ }^{3} \mathrm{P}_{1}$ & 363.214 & $23.1 \mathrm{C}$ & 3.29 & 0.91 & 37.87 & IRBD \\
\hline & & ${ }^{3} \mathrm{P}_{1}^{\mathrm{o}}-{ }^{3} \mathrm{P}_{1}$ & 376.585 & $23.9 \mathrm{~B}$ & 3.18 & 0.86 & 42.78 & IRBD \\
\hline 7. & $\left({ }^{2} \mathrm{P}^{\mathrm{o}}\right) 6 \mathrm{~s}-\left({ }^{2} \mathrm{P}^{\mathrm{o}}\right) 6 \mathrm{p}$ & ${ }^{1} \mathrm{P}_{1}^{\mathrm{o}}-{ }^{1} \mathrm{P}_{1}$ & 377.253 & $24.5 \mathrm{~B}$ & 3.24 & & 45.70 & IRBD \\
\hline 8. & $\left({ }^{2} D^{\circ}\right) 6 \mathrm{p}-\left({ }^{2} \mathrm{D}^{\circ}\right) 6 \mathrm{~d}$ & ${ }^{3} \mathrm{P}_{1}-{ }^{3} \mathrm{P}_{2}^{\mathrm{o}}$ & 328.791 & $41.1 \mathrm{~B}$ & 7.16 & & & \\
\hline
\end{tabular}
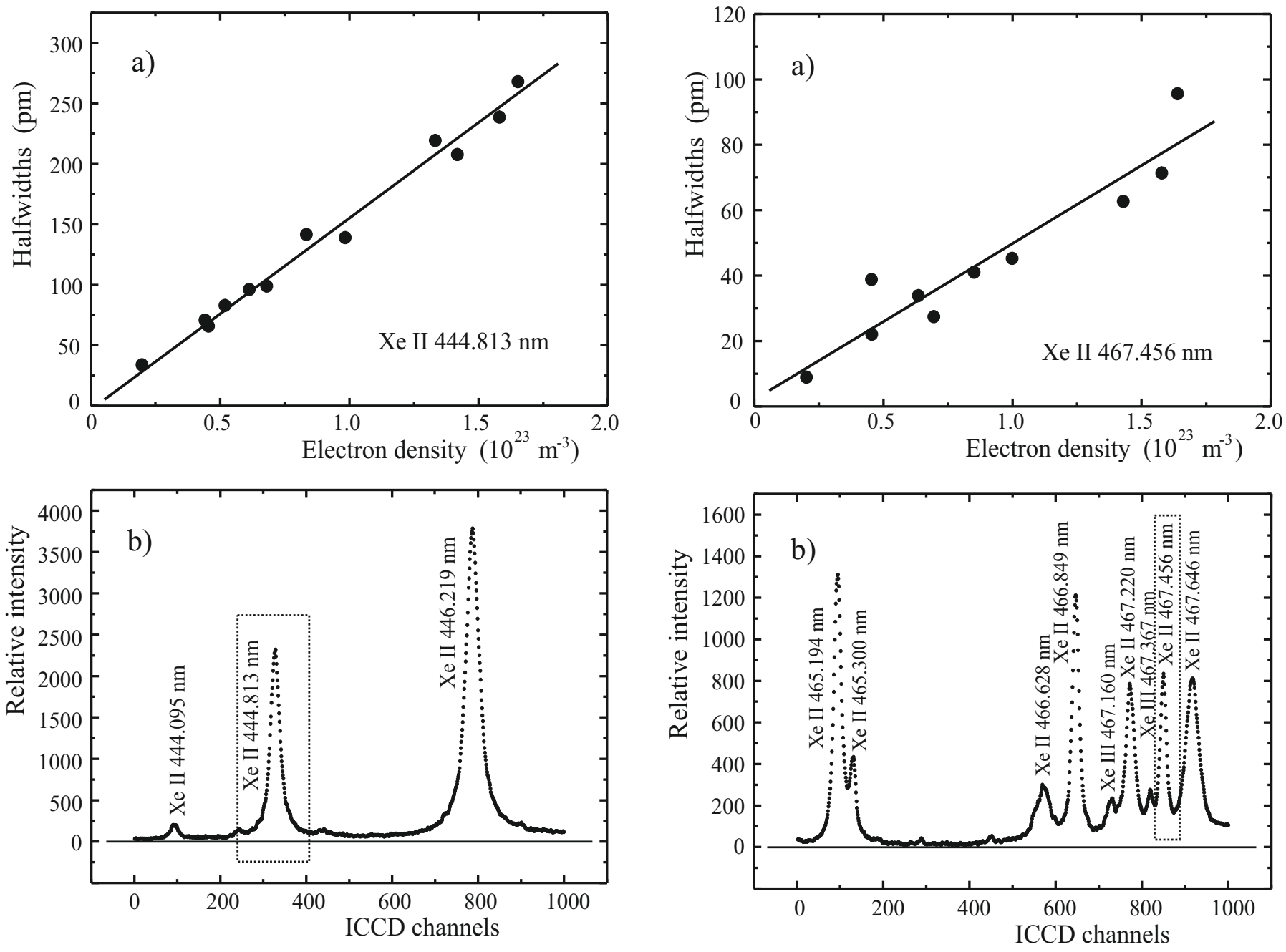

Fig. 4. Halfwidth dependence on electron density for Xe II $444.813 \mathrm{~nm}$ line a) and its experimental profile b).

Fig. 5. Halfwidth dependence on electron density for Xe II $467.456 \mathrm{~nm}$ line a) and its experimental profile b).

(Dimitrijević \& Konjević 1980), ( $\left.w_{\mathrm{m}} / w_{\text {calc }}\right)$, is given for two multiplets, 5 and 6 . Calculations were only performed in cases for which complete set of perturbing levels, necessary for modified semiempirical calculations (Dimitrijević \& Konjević 1980), were available in NIST data. For calculations, $L S$ coupling scheme was used. The ratio between measured and calculated halfwidths ranges between 0.8 and 0.9 , which can be considered as good agreement.

Experimental results of other authors (Konjević \& Pittman 1987; Iriarte et al. 1997; Romeo et al. 1998) are given in the eighth column of Table 3 . The present halfwidth result and halfwidth measured by Konjević \& Pittman (1987) for the $360.702 \mathrm{~nm}$ line from multiplet 2, is in good agreement with the ratio $w_{\mathrm{m}} / w=0.94$. The comparison between our results and those from other authors (Iriarte et al. 1997; Romeo et al. 1998) is fairly good only for two lines: $365.461 \mathrm{~nm}$ from 

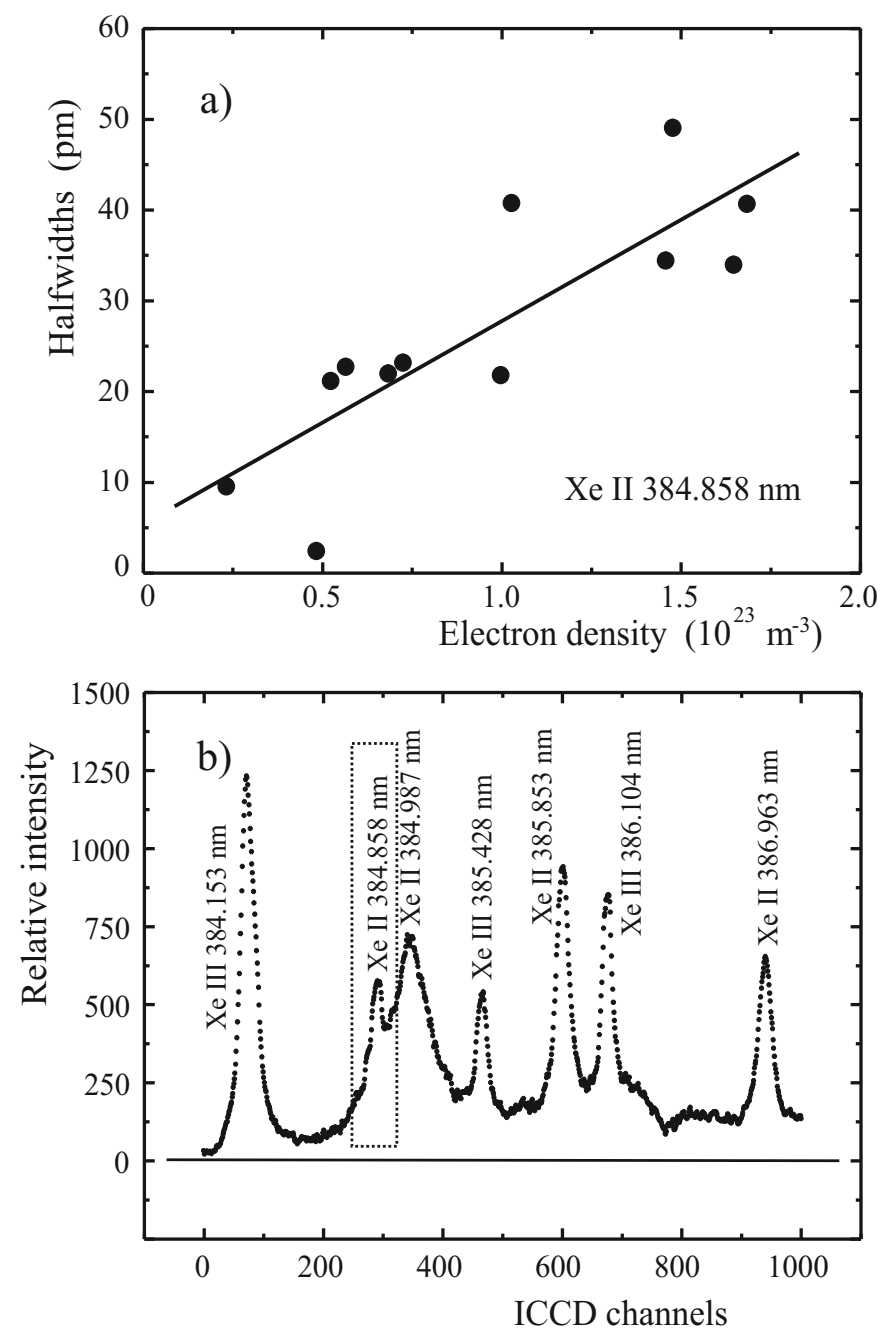

Fig. 6. Halfwidth dependence on electron density for Xe II 384.858 nm line a) and its experimental profile b).

multiplet 4, (ratio 0.75) and $467.367 \mathrm{~nm}$ from multiplet 5, (ratio 0.87). Comparisons to other available data from these two works give ratios between 0.4 and 0.6 .

\subsection{Xe III shift results}

Stark-shift results of 6 Xe III spectral lines from 6 multiplets are given in Table 4. It is organised in the same way as previous ones. The seventh column contains the comparison between the experimentally obtained Stark shift values $\left(d_{\mathrm{m}}\right)$ and the theoretical ones $\left(d_{\text {calc }}\right)$, calculated by a modified semiempirical formula (Dimitrijević \& Kršljanin 1986). Experimental shift results are also compared with the measured ones $(d)$ in Di Rocco (1990b)DR. Linear dependence of Stark shifts on electron density in case of Xe III lines is confirmed here, as well as in previous cases.

The complete set of perturbing data necessary for calculations based on modified semiempirical formula (Dimitrijević \& Kršljanin 1986) is available in the NIST database, only in the case of the $465.778 \mathrm{~nm}$ line from the multiplet 1 . The ratio $d_{\mathrm{m}} / d_{\text {calc }}$ is very low at only 0.18 . This is not unusual for comparison with theoretical data. In fact, in the case of Xe II, similar disagreement has already been found by the author of this modified semiempirical formula himself (Popović \& Dimitrijević 1996).

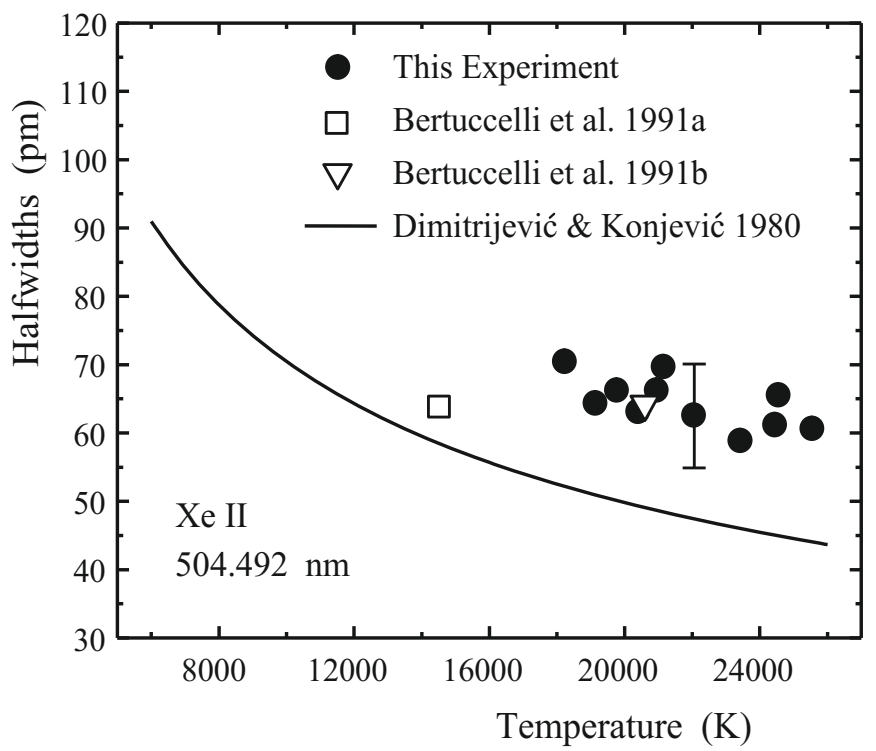

Fig. 7. Stark halfwidth of Xe II $504.492 \mathrm{~nm}$ line as a function of temperature.

There are only results from one work, by Di Rocco (1990b), available for comparison with the present Xe III measured Stark shift data. The ratios $d_{\mathrm{m}} / d$ are between 0.1 and 2.8 , but the sign of the shift is the same. There is one exception, the $377.632 \mathrm{~nm}$ line from multiplet 3, where there is not only a large difference between the present and Di Rocco (1990b) shift values, but the sign of the shift is opposite, as well. There is no reasonable explanation for these large differences except that Stark shift measurements are, in general, less accurate than Stark width measurements, especially in cases where shifts are very low. Here, as in the previous cases, shift results from Di Rocco (1990b) were scaled to $T_{\mathrm{e}}=22000 \mathrm{~K}$ (eighth column in Table 4).

\section{Conclusions}

Radiation from a low-pressure pulsed arc plasma has been studied to determine Stark parameters of some singly and doubly ionized xenon lines. In this work, only low-intensity lines were considered. All investigated spectral lines belong to UV and visible wavelength region, from $310 \mathrm{~nm}$ to $650 \mathrm{~nm}$. The results of 25 Stark halfwidths and 29 shifts of Xe II and 10 Stark halfwidths and 6 shifts of Xe III spectral lines are reported. Most of the Stark parameters data measured in this work are missing in the literature. Seventeen Xe II halfwidths, 28 Xe II shifts, and 2 Xe III halfwidths are presented for the first time in this paper.

In cases where Stark parameters of two lines belonging to the same multiplet were measured, the differences between their halfwidths and shifts are less than $10 \%$, which is in good agreement with the predicted intra-multiplet regular behaviour (Wiese \& Konjević 1982; Wiese \& Konjević 1992). This is a very good result, considering that experimental errors were relatively high. These errors stem from the low intensities of the investigated lines and sometimes from their overlapping with more intensive neighbouring lines.

The measured Stark parameters were compared with theoretical data calculated using modified semiempirical formula by Dimitrijević \& Konjević (1980) in case of halfwidth, and by Dimitrijević \& Kršljanin (1986) in the case of shift calculations. These calculations were performed only if the complete 
Table 4. Experimental Stark shifts of Xe III lines.

\begin{tabular}{|c|c|c|c|c|c|c|c|c|}
\hline No. & Configurations & Terms & $\begin{array}{l}\text { Wavelength } \\
(\mathrm{nm})\end{array}$ & $\begin{array}{r}d_{\mathrm{m}} \text { Acc } \\
(\mathrm{pm})\end{array}$ & $\begin{array}{r}d_{\mathrm{m}} \\
\left(10^{11} \mathrm{~s}^{-1}\right) \\
\end{array}$ & $d_{\mathrm{m}} / d_{\text {calc }}$ & $\begin{array}{r}d \\
(\mathrm{pm})\end{array}$ & Ref. \\
\hline 1. & $\left({ }^{2} \mathrm{D}^{\circ}\right) 6 \mathrm{~s}-\left({ }^{2} \mathrm{D}^{\circ}\right) 6 \mathrm{p}$ & ${ }^{1} \mathrm{D}_{2}^{\mathrm{o}-}-{ }^{1} \mathrm{P}_{1}$ & 465.778 & $-2.2 \mathrm{D}$ & 1.91 & 0.18 & -2.97 & DR \\
\hline 2. & $\left({ }^{2} \mathrm{D}^{\mathrm{o}}\right) 5 \mathrm{~d}-\left({ }^{2} \mathrm{P}^{\mathrm{o}}\right) 6 \mathrm{p}$ & ${ }^{3} \mathrm{~S}_{1}^{\mathrm{o}}-{ }^{3} \mathrm{P}_{1}$ & 330.680 & $-6.3 \mathrm{D}$ & 10.85 & & -2.23 & DR \\
\hline 3. & $\left({ }^{2} \mathrm{P}^{\mathrm{o}}\right) 6 \mathrm{~s}-\left({ }^{2} \mathrm{P}^{\mathrm{o}}\right) 6 \mathrm{p}$ & ${ }^{3} \mathrm{P}_{1}^{\mathrm{o}}-{ }^{3} \mathrm{D}_{2}$ & 377.632 & $-3.5 \mathrm{D}$ & 4.62 & & 11.53 & DR \\
\hline 4. & $\left({ }^{2} \mathrm{P}^{\mathrm{o}}\right) 6 \mathrm{~s}-\left({ }^{2} \mathrm{P}^{\mathrm{o}}\right) 6 \mathrm{p}$ & ${ }^{3} \mathrm{P}_{0}^{\mathrm{o}}-{ }^{3} \mathrm{P}_{1}$ & 363.214 & $-4.1 \mathrm{D}$ & 5.86 & & -2.70 & DR \\
\hline 5. & $\left({ }^{2} \mathrm{P}^{\mathrm{o}}\right) 5 \mathrm{~d}-\left({ }^{2} \mathrm{P}^{\mathrm{o}}\right) 6 \mathrm{p}$ & ${ }^{3} \mathrm{D}_{2}^{\mathrm{o}}-{ }^{3} \mathrm{~S}_{1}$ & 353.994 & $-2.2 \mathrm{D}$ & 3.31 & & -15.24 & DR \\
\hline 6. & $\left({ }^{2} \mathrm{P}^{\mathrm{o}}\right) 6 \mathrm{~s}-\left({ }^{2} \mathrm{P}^{\mathrm{o}}\right) 6 \mathrm{p}$ & ${ }^{1} \mathrm{P}_{1}^{\mathrm{o}}-{ }^{1} \mathrm{P}_{1}$ & 377.253 & $-7.7 \mathrm{D}$ & 10.19 & & -2.90 & DR \\
\hline
\end{tabular}

set of necessary perturbing level data was available in the NIST database. The agreement found between our measured results and calculated Stark parameters is fairly good, except for one $\mathrm{Xe}$ III shift result where the reatio $d_{\mathrm{m}} / d_{\text {calc }}$ is 0.18 .

The Stark parameters experimentally determined in this work were also compared to other previous experimental results for Xe II halfwidths (Pittman \& Konjević 1986; Lesage et al. 1989; Bertuccelli et al. 1991a; Bertuccelli et al. 1991b; Gigosos et al. 1994), for Xe II shifts (Gigosos et al. 1994), for Xe III halfwidths (Konjević \& Pittman 1987; Iriarte et al. 1997; Romeo et al. 1998), and for Xe III shifts (Di Rocco 1990b). As a general remark, we can conclude that our measured Stark parameters are in good agreement with data from Pittman \& Konjević (1986), Gigosos et al. (1994) and Konjević \& Pittman (1987). The comparison with data from Bertuccelli et al. (1991a), Bertuccelli et al. (1991b), Iriarte et al. (1997), and Romeo et al. (1998) show some agreement in some cases and strong disagreement in others.

In general, the comparison of our results with other experimental and theoretical data, as well as the intra-multiplet analysis, must be considered as satisfying, especially if one takes the quality of the observed spectral line profiles into account. Exceptions are Xe III shift results, where an obvious disagreement exists with the results from Di Rocco (1990b). Otherwise, it is well known that line shifts are less accurate than line halfwidths, both measured and calculated. New measurements will be useful for clarifying these disagreements.

Present Stark data, in general, can be used for diagnostic purposes, demonstration of regularities, and similarities of line halfwidths or shifts within the multiplets, or by combining them with other experimental results, within the supermultiplets or transition arrays. In addition, these results can be used for testing theory, and they are also of interest in astrophysics.

Stark parameters are useful for equivalent-width calculations (Lanz et al. 1988) for stellar atmosphere temperatures above $7000 \mathrm{~K}$. Low-intensity spectral lines are also of interest in astrophysics (Castelli \& Hubrig 2004). The collection of Stark parameters presented in this work, which completes our previous measurements for Xe II and Xe III (Djurović et al. 2006; Peláez et al. 2006; Ćirišan et al. 2007), can be used for estimating the abundance of xenon in astrophysical objects, such as HgMn stars or progenitor stars in the Planetary nebulae.

Acknowledgements. We gratefully thank S. González for his collaboration in the experimental arrangement, the Spanish Dirección General de Investigación Científica y Técnica (Ministerio de Educación y Ciencia), and the Consejería de Educación y Cultura de Castilla y León for their financial support under contract nos. FIS2005-03155 and VA015A05. S. Djurović and M. Cirišan thank the Ministry of Science, Technology, and Development, Republic of Serbia for partial support (141024). Dr J. A. Aparicio would like to express his personal acknowledgement to the Organización Nacional de Ciegos de España (ONCE) for its help.

\section{References}

Adelman, S. J. 1992, MNRAS, 258, 167

Adelman, S. J., Philip, A. G. D., \& Adelman C. J. 1996, MNRAS, 282, 953

Aparicio, J. A., Gigosos, M. A., González, V. R., et al. 1998a, J. Phys. B, 31, 1029

Aparicio, J. A., Pérez, C., del Val, J. A., et al. 1998b, J. Phys. B: At. Mol. Opt. Phys., 31, 4909

Bayón, R., García, M., Gigosos, M. A., \& Mar, S. 1994, Actas de la IV Reunión Nacional de Óptica (Granada, Spain), 385

Bertuccelli, D., \& Di Rocco, H. O. 1993, Phys. Scr., 47, 747

Bertuccelli, D., Bertuccelli, G., \& Di Rocco, H. O. 1991a, Phys. Scr., 43, 469

Bertuccelli, D., Bertuccelli, G., \& Di Rocco, H. O. 1991b, Rev. Sci. Instrum., 62, 966

Bidelman, W. P. 1964, Proc. Symp. 26, (Utrecht, Netherlands), ed. H. Hubert (London: IAU, Academic), 229

Bord, D. J., Cowley, C. R., Hubrig, S., \& Bidelman, W. P. 2003, Am. Astron. Soc. Meeting (Nashville, USA), 202, 3210

Castelli, F., \& Hubrig, S. 2004, A\&A., 425, 263

Ćirišan, M., Peláez, R. J., Djurović, S., Aparicio, J. A., \& Mar, S. 2007, J. Phys. B: At. Mol. Opt. Phys., 40, 3477

Davies, J. T., \& Vaughan, J. M. 1963, ApJ, 137, 1302

de la Rosa, M. I., Pérez, C., de Frutos, A. M., \& Mar, S. 1990, Phys. Rev. A, 42, 7389

del Val, J. A., Mar, S., Gigosos, M. A., et al. 1998, Jpn. J. Phys., 37, 4177

Dimitrijević, M. S. 2003, Astron. Astrophys. Trans., 22, 389

Dimitrijević, M. S., \& Konjević, N. 1980, J. Quant. Spectrosc. Radiat. Transf., 24,451

Dimitrijević, M. S., \& Kršljanin, V. 1986, A\&A, 165, 269

Di Rocco, H. O. 1990a, J. Appl. Phys., 68, 3732

Di Rocco, H. O. 1990b, Spectrosc. Lett. 23, 283

Di Rocco, H. O. 1990c, Nuovo Cimento, 12 D, 1485

Djurović, S., Peláez, R. J., Ćirišan, M., Aparicio, J. A., \& Mar, S. 2006, J. Phys. B: At. Mol. Opt. Phys., 39, 2901

Dworetsky, M. M., Persaud, J. L., \& Patel, K. 2008, MNRAS, 385, 1523

Gigosos, M. A., Mar, S., Pérez, C., \& de la Rosa, I. 1994, Phys. Rev. E, 49, 1575 Griem, H. R. 1964, Plasma spectroscopy (Academic Press)

Griem, H. R. 1974, Spectral line broadening by plasmas (Academic Press)

Hansen, J. E., \& Persson, W. 1987, Phys. Scr. 36, 602

Iglesias, C. A., Rogers, F. J., \& Wilson, B. G. 1990, ApJ, 360, 221

Iriarte, D., Romeo y Bidegain, M., Bertuccelli, G., \& Di Rocco, H. O. 1997, Phys. Scr., 55, 181

Karakas, A. I., van Raai, M. A., Lugaro, M., Sterling, N. C., \& Dinerstein, H. L. 2009, ApJ, 690, 1130

Konjević, N., \& Pittman, T. L. 1987, J. Quant. Spectrosc. Radiat. Trans., 37, 311 Konjević, N., \& Uzelac, N. I. 1990b, J. Quant. Spectrosc. Radiat. Trans., 44, 61 Konjević, N., \& Wiese, W. L. 1990a, J. Phys. Chem. Data, 19, 1307

Konjević, N., Dimitrijević, M. S., \& Wiese, W. L. 1984, J. Phys. Chem. Data, 13,649

Konjević, N., Lesage, A., Fuhr, J. R. \& Wiese, W. L. 2002, J. Phys. Chem. Data, 31,819

Lanz, T., \& Artru, M. C. 1987, Workshop on Elemental Analyses, Lausanne, ed. S. J. Adelman, \& T. Lanz (unpublished)

Lanz, T., Dimitrijević, M. S., \& Artru, M. C. 1988, A\&A, 192, 249

Lesage, A. 2009, New Astron. Rev., 52, 471

Lesage, A., Miller, M. H., Richou, J., \& Bach, T. 1981, Spectral Line Shapes, ed. B. Wende (Walter De Gruyter), 257

Lesage, A., Abadie, D., \& Miller, M. H. 1989, Phys. Rev. A, 40, 1367

Manola, S., Konjević, N., Richou, J., Lebrun, J. L., \& Lesage, A. 1988, Phys. Rev. A, 38, 5742

Miller, M. H., Lesage, A., \& Abadie, D. 1982, Phys. Rev. A, 25, 2064

Nick, K. P., \& Helbig, V. 1986, Phys. Scr., 33, 55 
NIST, Atomic spectra database, http://physics.nist.gov./asd Peláez, R. J., Ćirišan, M., Djurović, S., Aparicio, J. A., \& Mar, S. 2006, J. Phys. B: At. Mol. Opt. Phys., 39, 5013

Pequignot, D., \& Baluteau, J.-P. 1994, A\&A, 283, 593

Pintado, O. I., \& Adelman, S. J. 1996, A\&AS, 118, 283

Pittman, T. L., \& Konjević, N. 1986, J. Quant. Spectrosc. Radiat. Transfer, 35, 247

Popović, L. C., \& Dimitrijević, M. S. 1996, A\&ASS, 116, 359

Richou, J., Manola, S., Lebrun, J. L., \& Lesage, A. 1984, Phys. Rev. A, 29, 3181

Romeo y Bidegain, M., Iriarte, D., Bertuccelli, G., \& Di Rocco, H. O. 1998, Phys. Scr., 57, 495

Ryabchikova, T. A., Malanushenko, V. P., \& Adelman, S. J. 1999, A\&A., 351, 963

Sadakane, K. 1993, ed. M. M. Dworetsky, F. Castelli, \& R. Faraggiana, ASP Conf. Ser., 44,72
Sadakane, K., Takada-Hidal, M., Takeda, Y., et al. 2001, Pub. Astron. Soc. Japan, 53,1223

Seidel, S., Wrubel, Th., Roston, G., \& Kunze, H.-J. 2001, J. Quant. Spectrosc. Radiat. Transf., 71, 703

Sharpee, B., Zhang, Y., Williams, R., et al. 2007, ApJ, 659, 1265

Striganov, A. R., \& Sventitskii, N. S. 1968, Tables of Spectral Lines of Neutral and Ionized Atoms (Plenum)

Vitel, Y., \& Skowronek, M. 1987, J. Phys. B: At. Mol. Phys., 20, 6493

Whitford, A. E. 1962, Astron. J., 67, 608

Wiese, W. L., \& Konjević, N. 1982, J. Quant. Spectrosc. Radiat. Transfer, 28, 185

Wiese, W. L., \& Konjević, N. 1992, J. Quant. Spectrosc. Radiat. Transfer, 47, 185

Zhang, Y., Liu, X.-W., Luo, S.-G., Pequignot, D., \& Barlow, M. J. 2005, A\&A, 442, 249 